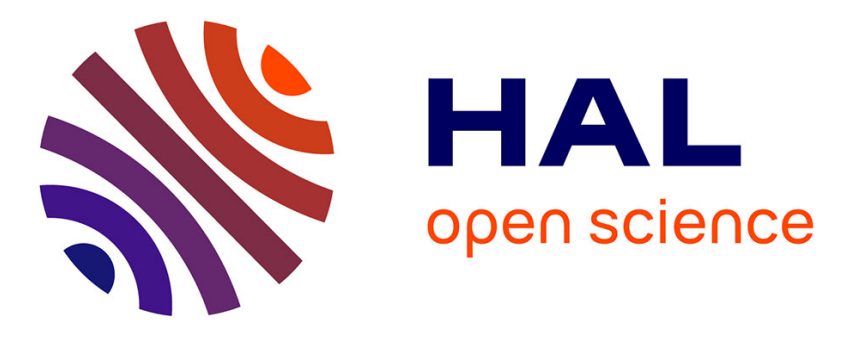

\title{
Reconfigurable 4-Arm Spiral Antenna for Dual Polarization
}

Israël Hinostroza, Régis Guinvarc', Randy L Haupt

\section{To cite this version:}

Israël Hinostroza, Régis Guinvarc', Randy L Haupt. Reconfigurable 4-Arm Spiral Antenna for Dual Polarization. 2020 IEEE International Symposium on Antennas and Propagation and North American Radio Science Meeting, Jul 2020, Quebec, Canada. 10.1109/IEEECONF35879.2020.9329949 . hal03194789

\section{HAL Id: hal-03194789 \\ https://hal.science/hal-03194789}

Submitted on 9 Apr 2021

HAL is a multi-disciplinary open access archive for the deposit and dissemination of scientific research documents, whether they are published or not. The documents may come from teaching and research institutions in France or abroad, or from public or private research centers.
L'archive ouverte pluridisciplinaire HAL, est destinée au dépôt et à la diffusion de documents scientifiques de niveau recherche, publiés ou non, émanant des établissements d'enseignement et de recherche français ou étrangers, des laboratoires publics ou privés. 


\section{Reconfigurable 4-Arm Spiral Antenna for Dual Polarization}

\author{
Israel Hinostroza Sáenz \\ SONDRA \\ CentraleSupélec
}

Gif-sur-Yvette, France

israel.hinostroza@centralesupelec.fr

\author{
Régis Guinvarc'h \\ SONDRA \\ CentraleSupélec \\ Gif-sur-Yvette, France \\ regis.guinvarch@centralesupelec.fr
}

\author{
Randy L. Haupt \\ Electrical Engineering of Computer Science \\ Colorado School of Mines \\ Golden, Colorado \\ rhaupt@ieee.org
}

\begin{abstract}
-4-arm spiral antennas have a wide bandwidth and circular polarization when operating in mode 1 (fundamental mode). Switching to mode 3 (to obtain opposite circular polarization) dramatically reduces the antenna bandwidth compared to mode 1 . In this work we reduce the arm sizes of the spiral (for example with RF switches) to increase the bandwidth of mode 3 at the higher mode 1 frequencies. In this way the antenna has the same wide bandwidth for both polarizations (modes).

Index Terms-4-arm spiral antenna, archimedean spiral, reconfigurable antenna, circular polarization, spiral antenna modes
\end{abstract}

\section{INTRODUCTION}

Spiral antennas provide circular polarization over a wide bandwidth. The 4-arm spiral antenna has a polarization that depends on the induced mode [1]. Mode 1 is the fundamental mode that has a polarization in the same sense of the winding of the arms of the spiral. Mode 3 produces the opposite circular polarization to mode 1 . Mode 2 and mode 4 produce linear polarization with the slant direction dependent on the frequency.

It has been shown in [2] that mode 3 has circular polarization over a narrower bandwidth compared to mode 1 . In order to overcome this problem, a low-profile cavity (distance optimized) was proposed.

In this work we adapt the arm lengths of the spiral antenna in order to reduce the size of the antenna and increase its operating frequency.

\section{BANDWIDTHS OF MODE 3}

Our simulations were modeled using the full-wave solver FEKO [3]. The antenna is a self-complementary 4-arm Archimedean spiral with perfect electric conductor, right-hand winding, center feeding, 3.5 turns each arm, free space (no cavity, no substrate) and $8.5 \mathrm{~cm}$ of outer radius. The feeding phases for mode 3, left-hand (LH) polarization, are shown in Fig. 1.

In Fig. 2 we can see three spirals, same dimmensions but having gaps (or not) in order to try to reduce the effective arm length of the spirals. The gaps simulate RF switches (as a first approach). Each gap is $0.58 \mathrm{~cm}$ long and positioned at the same distance on each arm, hence 4 gaps at a time.

Fig. 3 shows the gain (mode 3, LH polarization in our case) versus frequency of the spirals in Fig. 2. We can see that the

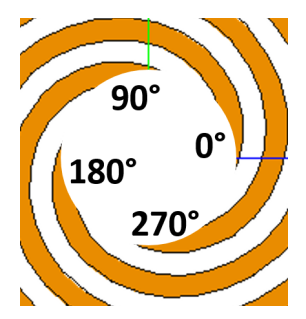

Fig. 1. Feeding spiral to induce mode 3.
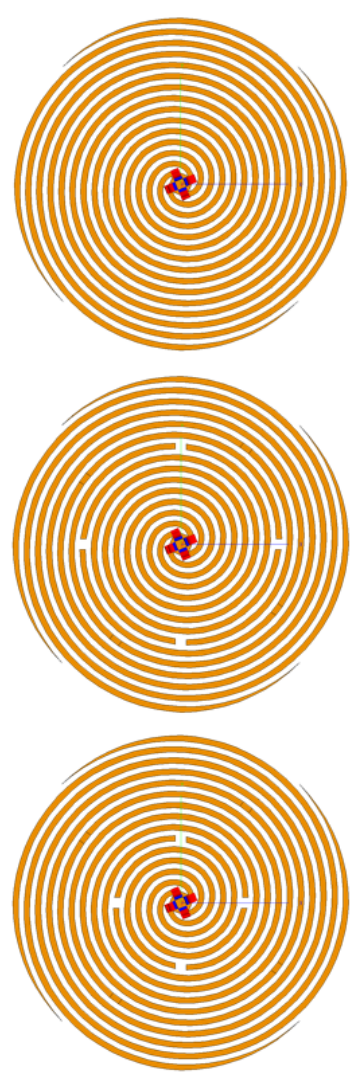

Fig. 2. From top to bottom: full spiral, with arm gap at 1.9 turns and with arm gap at 1.2 turns. 


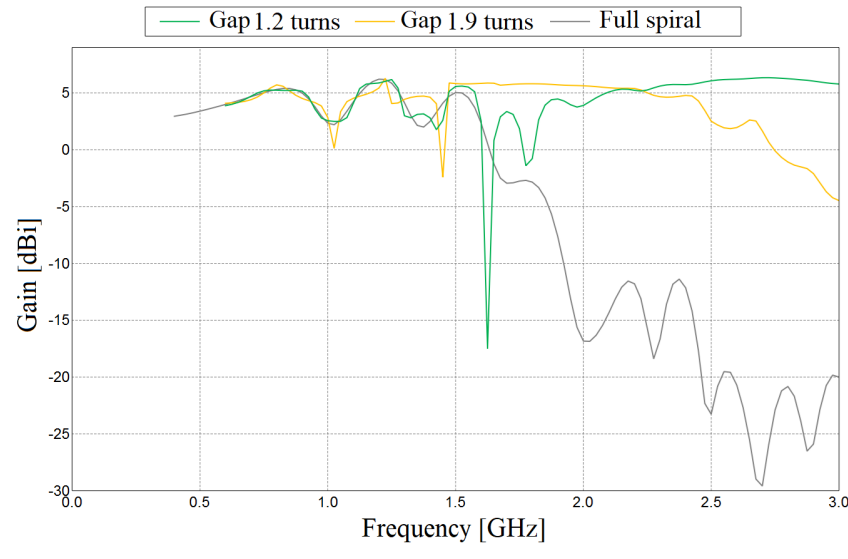

Fig. 3. Gain, mode 3, versus frequency of the three spirals of Fig. 2

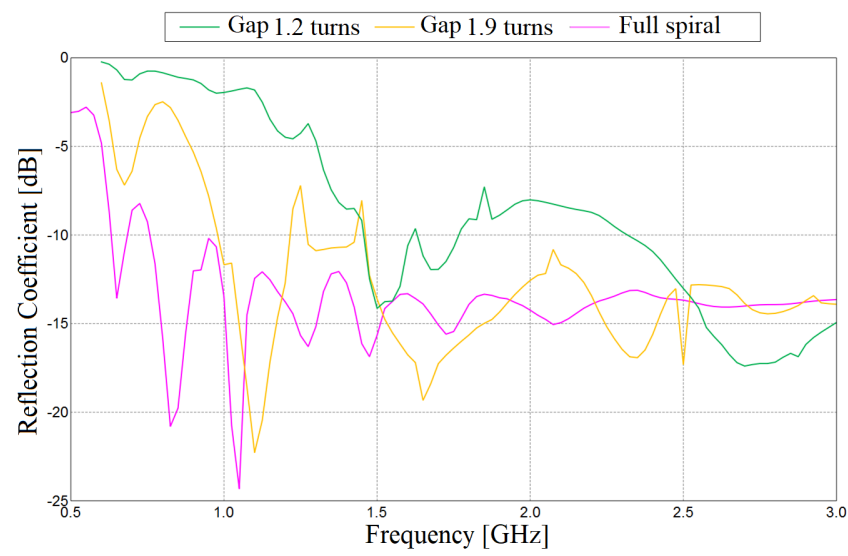

Fig. 4. Reflection coefficient, mode 3, versus frequency of the three spirals of Fig. 2

gain of the full spiral is reduced for frequencies higher than 1.6 GHz. We can also see that introducing the gaps recovers the gain at high frequencies, thus showing the efficacy of gap.

However, some strong narrow dips appear when using the gaps. For example, a dip of about $15 \mathrm{~dB}$ appears at $1.6 \mathrm{GHz}$ when the gap is positioned at 1.2 turns. Simulations have shown that this is due to the coupling between the inner part (before the gap, starting from center) and outer part of the spiral antenna.

Fig. 4 is a plot of the reflection coefficient of each arm $\left(Z_{r e f}=100 \Omega\right)$. We can see that introducing the gaps shifts the low cut-off frequency of the reflection coefficients towards higher frequencies. This is expected as the gaps are reducing the effective length of the arms. This reduction on the effective size of the antenna can be clearly seen by calculating their theoretical low cut-off frequency (using ring theory, see [4]) corrected due to reflections at the end of the arms (see [5]), or in this case reflections at the gap.

Table I shows the low cut-off frequency $\left(f_{\text {low }, p}\right)$ versus outer radius (when gaps, this radius is the position of the gaps) of the spirals using a correction factor of $p=1.1$ (taking as reference the spiral without gaps and Ref. Coeff. $<-10 \mathrm{~dB}$,
TABLE I

LOW CUT-OFF FREQUENCY VERSUS EFFECTIVE SIZE OF ANTENNA $p=1.1$, SEE FIG. 4 .

\begin{tabular}{|c|c|c|c|}
\hline radius $[\mathrm{cm}]$ & $f_{\text {low }, p}[\mathrm{GHz}]$ & $f_{\text {simu. }}[\mathrm{GHz}]$ & Comments \\
\hline 8.5 & 0.62 & 0.62 & reference for $p$ \\
5.4 & 0.97 & 0.95 & gap at 1.9 turns \\
3.6 & 1.46 & 1.45 & gap at 1.2 turns \\
\hline
\end{tabular}

see Fig. 4). Similar to the case of the gain, in Fig. 4 we can see some peaks at the same frequencies of the gain dips in Fig. 3.

From these results we can see that RF switches (simulated as gaps here) at different positions shift the working frequency of the spiral operating in mode 3 . In Table II we position the switches (ON no gap, OFF gap) to cover a wide bandwidth $(0.62$ to $3 \mathrm{GHz})$ of mode 3 . Switch inner $_{\text {and }}$ Switch outer are positioned at 1.2 turns and 1.9 turns from the center (as in Fig. 2), respectively.

TABLE II

CONFIGURATION OF SWITCHES FOR MODE 3 WIDE BANDWIDTH

\begin{tabular}{|c|c|c|}
\hline Switch inner $_{\text { }}$ & Switch $_{\text {outer }}$ & Frequency band $[\mathrm{GHz}]$ \\
\hline ON & ON & $0.62-1.5$ \\
ON & OFF & $1.5-2.4$ \\
OFF & OFF & $2.4-3$ \\
\hline
\end{tabular}

From Table I and Table II, it is clear that the position and number of the switches let us choose the length and number of the instantaneous bandwiths on mode 3 .

\section{CONCLUSIONS}

A 4-arm spiral antenna without a ground plane has a wide bandwidth when its fundamental mode (mode 1) is excited. Inducing the opposite polarization (mode 3 ) significantly reduces its mode 1 bandwidth, because the antenna becomes too large.

In this work, it has been shown that using switches (simulated as gaps here) on the arms of the spiral leads to a reduction on the effective size of the antenna and, hence, increasing its bandwidth in mode 3 (opposite polarization) even to the same bandwidth of the fundamental mode. The position and number of the switches provides a choice on the length and number of the instantaneous bandwiths on mode 3 .

\section{REFERENCES}

[1] R. G. Corzine and J. A. Mosko, Four-arm Spiral Antennas, 1st ed., Artech, 1990.

[2] H.R. Fang, M. Serhir, R. Guinvarc'h, and K. Mouthaan, "Enhanced dualcircular polarised four-arm Archimedean spiral antenna with low-profile cavity backing," IET Microwaves, Ants. \& Prop., vol. 9, no. 12, pp. 1260-1266, September 2015.

[3] Altair Feko, 2019.

[4] J. A. Kaiser, "The archimedean two-wire spiral antenna," IRE Trans. on Ants. \& Prop., vol. 8, no. 3, pp. 312-323, May 1960.

[5] I. Hinostroza, R. Guinvarc'h and R. L. Haupt, "Estimating the Bandwidth of Spiral Antenna Arrays," IEEE AWPL, vol. 15, pp. 1317-1340, 2016 